\title{
Minimization of the stator current in induction motor with defined load on the shaft by maintaining optimum absolute slip
}

\author{
V. N. Meshcheryakovi,,,$V . V$. Danilov $^{1}, S h . R$. Khasanov ${ }^{2}$, and $S$. Valtchev $^{3}$ \\ ${ }^{1}$ Lipetsk State Technical University, Lipetsk, Russia \\ ${ }^{2}$ Kazan State Power Engineering University, Kazan, Russia \\ ${ }^{3}$ Universidade Nova de Lisboa, Caparica, Portugal
}

\begin{abstract}
This paper presents the study of induction motor operation with regulated frequency and voltage while maintaining the absolute slip of the two optimal modes - with a minimum of the "stator current / torque" ratio and a minimum of the "winding loss / torque" ratio; the results of experimental studies confirm the validity of the analytical expressions.
\end{abstract}

\section{Introduction}

In standard open-loop electric drive systems with frequency regulated induction motor and scalar control, magnitude of the motor absolute slip in steady state depends on the rigidity of mechanical characteristic and on torque on the motor shaft. The absolute slip is usually not controlled and not regulated. Since the rigidity of the mechanical characteristic depends on the supply voltage of the stator winding, it is possible to change the rigidity of static mechanical characteristic with the given load on the motor shaft by adjusting the voltage reference signal.

Frequency regulated electric drive systems are widely used in industry, therefore, their research and improvement continues [1-3]. An important area of research is energy efficiency $[4,5]$. It is possible to increase the energy performance of a frequency regulated electric drive by using the optimal control system settings [6-10]. The optimal control of the inverter supplying the induction motor is studied in [1113]. The energy performance of an induction motor can be improved by regulating the voltage when the load of the motor changes [14-15].

The impact of the absolute slip on the stator current of induction motor with a given load on the motor shaft is discussed below.

\section{Theoretical part}

Parameters of frequency-regulated induction motor are described by relative values as [16]:

$$
\begin{gathered}
\alpha=\mathrm{f}_{1} / \mathrm{f}_{1 \mathrm{n}}=\omega_{1 \mathrm{el}} / \omega_{0 \mathrm{el}} \\
\beta=\mathrm{f}_{2} / \mathrm{f}_{1 \mathrm{H}}=\Delta \omega / \omega_{0}=\alpha \cdot \mathrm{S}_{\alpha} ; \\
\mathrm{S}_{\alpha}=\left(\omega_{1}-\omega\right) / \omega_{1}=\Delta \omega / \omega_{1}=\Delta \omega_{\mathrm{el}} / \omega_{1 \mathrm{el}}
\end{gathered}
$$

where $\alpha$ - relative frequency; $\beta$ - absolute slip; $S_{\alpha}-$ relative slip; $f_{1}$ - frequency of the stator supply voltage; $\mathrm{f}_{1 \mathrm{n}}$ - rated frequency of the stator supply voltage; $\mathrm{f}_{2}-$ frequency of the rotor current; $\omega_{1 \mathrm{el}}-$ circular frequency of the stator supply voltage from the frequency converter; $\omega_{0 \mathrm{el}}-$ angular frequency of the rated voltage; $\omega_{0}$ - rotation frequency of the stator field at the nominal frequency $\mathrm{f}_{1 \mathrm{n}} ; \omega_{1}$ - frequency of the stator field rotation at a frequency $\mathrm{f}_{1} ; \Delta \omega$ - absolute deviation of the rotor angular velocity; $\Delta \omega_{\mathrm{el}}=\Delta \omega \cdot \mathrm{p}_{\mathrm{n}}=\omega_{2}-$ reduced to an electric circuit, the absolute deviation of the rotor speed, equal to the circular electric frequency of the emf and the rotor current; $\mathrm{p}_{\mathrm{n}}$ - number of the motor poles pairs.

From formula (2) it follows that the absolute slip linearly depends on the absolute deviation of the rotor angular velocity, which determines the slope of the static mechanical characteristic (Figure 1), expressed by absolute value of rigidity [17]:

$$
\beta=\left|-\frac{\Delta \mathrm{M}}{\Delta \omega}\right|
$$

where $\Delta \mathrm{M}=\mathrm{M}_{\mathrm{C}}-$ deviation of the torque that is equal to the static torque of the motor.

\footnotetext{
* Corresponding author: mesherek@yandex.ru
} 


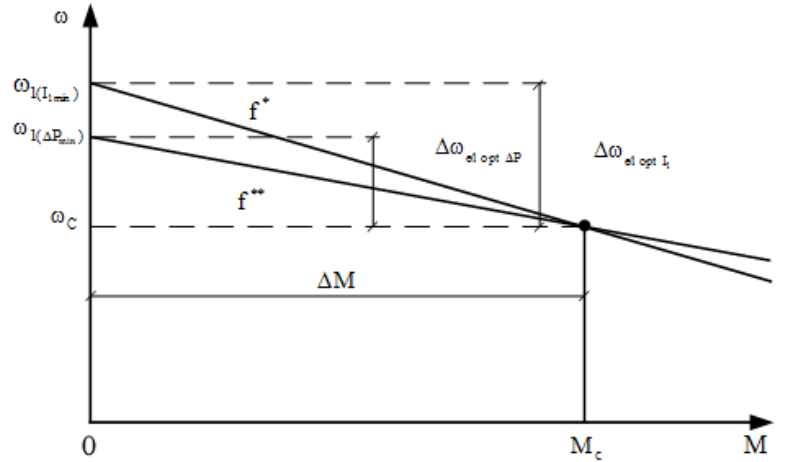

Fig. 1. Variation in mechanical characteristics of rigidity in induction motor with different control system settings.

The effective values of the rotor and stator currents are connected by the following formula:

$$
\mathrm{I}_{2}^{\prime}=\mathrm{I}_{1} \cdot \frac{\mathrm{x}_{\mathrm{m}}}{\sqrt{\left(\mathrm{x}_{\mathrm{m}}+\mathrm{x}_{2}^{\prime}\right)^{2}+\mathrm{R}_{2}^{\prime 2} / \beta^{2}}}
$$

The equivalent circuit shows that the parameter $\alpha$ affecting absolute slip $\beta$ and varying with frequency control, has a direct impact on the resistance of the circuit branches and the distribution of the currents.

The torque of induction motor with frequency control in static mode is [16]:

$$
\mathrm{M}=\frac{3 \cdot \mathrm{R}_{2}^{\prime} \cdot \mathrm{I}_{2}^{\prime 2}}{\omega_{0} \cdot \beta}=\frac{3 \cdot \mathrm{R}_{2}^{\prime} \cdot \mathrm{I}_{2}^{\prime 2}}{\Delta \omega}=\frac{3 \cdot \mathrm{p}_{\mathrm{n}} \cdot \mathrm{R}_{2}^{\prime} \cdot \mathrm{I}_{2}^{\prime 2}}{\Delta \omega_{\mathrm{el}}}
$$

Solving equations (5) and (6) with regard to expressions (2) and (3), we obtain the relation of the stator current and the torque

$$
\mathrm{I}_{1}=\sqrt{\mathrm{M}} \cdot \sqrt{\frac{\left(\mathrm{L}_{\mathrm{m}}+\mathrm{L}_{2 \sigma}^{\prime}\right) \cdot \Delta \omega_{\mathrm{el}} / \mathrm{R}_{2}^{\prime}+\mathrm{R}_{2}^{\prime} / \Delta \omega_{\mathrm{el}}}{3 \cdot \mathrm{p}_{\mathrm{n}} \cdot \mathrm{L}_{\mathrm{m}}^{2}}}
$$

The following relation connects the rotor flux linkage and the stator current of the induction motor in the operator form [18]:

$$
\Psi_{2}(\mathrm{p})=\mathrm{I}_{1}(\mathrm{p}) \cdot \mathrm{L}_{\mathrm{m}} \cdot \frac{1}{\mathrm{~T}_{2} \mathrm{p}+1}
$$

where $T_{2}$ is the rotor time constant:

$$
\mathrm{T}_{2}=\frac{\mathrm{L}_{2}^{\prime}}{\mathrm{R}_{2}^{\prime}}=\frac{\mathrm{L}_{2 \sigma}^{\prime}+\mathrm{L}_{\mathrm{m}}}{\mathrm{R}_{2}^{\prime}}
$$

The phase frequency characteristic of the first order aperiodic link at the frequency $\omega=\Delta \omega_{\mathrm{el}}$ is

$$
\varphi_{0}^{\prime}\left(\Delta \omega_{\mathrm{el}}\right)=\operatorname{arctg}\left(\mathrm{T}_{2} \cdot \Delta \omega_{\mathrm{el}}\right)=\operatorname{arctg} \frac{\mathrm{L}_{2}^{\prime} \Delta \omega_{\mathrm{el}}}{\mathrm{R}_{2}^{\prime}}
$$

The variable losses on active resistance of stator winding are determined by:

$$
\Delta \mathrm{P}=3 \cdot\left(\mathrm{I}_{1}^{2} \mathrm{R}_{1}+\mathrm{I}_{2}^{\prime 2} \mathrm{R}_{2}^{\prime}\right)
$$

Solving equations (11), (6) and (7), taking into account expressions (2) and (3), we obtain the following expression:

$$
\begin{aligned}
& \Delta \mathrm{P}=3 \cdot \frac{\mathrm{M} \cdot \Delta \omega_{\mathrm{el}}}{3 \cdot \mathrm{R}_{2}^{\prime} \cdot \mathrm{p}_{\mathrm{n}}} * \\
& *\left(\frac{\left(\mathrm{L}_{\mathrm{m}}+\mathrm{L}_{2 \sigma}^{\prime}\right)^{2}+\mathrm{R}_{2}^{\prime 2} / \Delta \omega_{\mathrm{el}}^{2}}{\mathrm{~L}_{\mathrm{m}}^{2}} \mathrm{R}_{1}+\mathrm{R}_{2}^{\prime}\right)
\end{aligned}
$$

Table 1 shows the results of finding the minimum ratio "stator current/torque" based on study of expression (7), and "loss in windings/torque" based on study of expression (12).

It is possible to adjust the rigidity of the mechanical characteristics in induction motor at a fixed frequency of the supply voltage by changing the effective value of the voltage. In the practical implementation of the correction systems [19-22], it is more convenient to tune the "stator current/torque" ratio to a minimum, since the static characteristics have a lower required rigidity in this case, therefore, less voltage correction required than linear frequency control $\mathrm{u} / \mathrm{f}=$ const. The optimal operation mode of the induction motor in the frequency electric drive system can be implemented using the unsaturated magnetic circuit, when the static torque does not exceed the nominal value of $\mathrm{M}_{\mathrm{C}} \leq \mathrm{M}_{\mathrm{N}}$. In this case, the drive control system, configured to a minimum of the "stator current / torque" ratio, should provide the optimum angle value $=45^{\circ}$

\section{Description of the experimental procedure}

To confirm the analytical results, we carry out experimental studies of variable-frequency induction drive with scalar control. The frequency converter was controlled according to the law $\mathrm{U} / \mathrm{f}=$ const using additional corrections of this control law.

The purpose of the experimental studies was to find the dependence of the stator current on the difference $\Delta \omega$ between the speed of the stator rotating field and the rotor speed, and the search for the optimal value $\Delta \omega_{\text {opt }}$ in which the stator current is minimal.

The experiment consists in changing the voltage and frequency supplied to the stator winding while ensuring that the drive operates with fixed static torque on the motor shaft and fixed rotation speed. In this case, the search for the optimal difference between the speed of the stator rotating field and the rotor speed is carried out by introducing an additional set point in increments of $1 \mathrm{~Hz}$ into the frequency reference channel, and stabilizing the motor shaft rotation speed by changing the voltage amplitude. 
Table 1. The relation between variables and criteria of optimal systems.

\begin{tabular}{|c|c|c|}
\hline Criterion & $\begin{array}{l}\text { Minimal ratio "stator current/motor torque" } \\
\qquad\left(\mathrm{I}_{1 \text { min }}\right)\end{array}$ & $\begin{array}{l}\text { Minimal energy loss in the motor windings } \\
\qquad\left(\Delta \mathrm{P}_{\min }\right)\end{array}$ \\
\hline $\begin{array}{l}\text { Initial equations } \\
\text { with effective } \\
\text { variables values }\end{array}$ & $\mathrm{I}_{1}^{2}=\mathrm{M} \frac{\Delta \omega_{\mathrm{el}}}{3 \mathrm{R}_{2}^{\prime} \cdot \mathrm{p}_{\mathrm{n}}} \cdot \frac{\left(\mathrm{L}_{\mathrm{m}}+\mathrm{L}_{2 \sigma}^{\prime}\right)^{2}+\mathrm{R}_{2}^{\prime 2} / \Delta \omega_{\mathrm{el}}^{2}}{\mathrm{~L}_{\mathrm{m}}^{2}}$ & $\begin{array}{c}\Delta \mathrm{P}=3 \cdot \frac{\mathrm{M} \cdot \Delta \omega_{\mathrm{el}}}{3 \mathrm{R}_{2}^{\prime} \cdot \mathrm{p}_{\mathrm{n}}} \times \\
\times\left(\frac{\left(\mathrm{L}_{\mathrm{m}}+\mathrm{L}_{2 \sigma}^{\prime}\right)^{2}+\mathrm{R}_{2}^{\prime 2} / \Delta \omega_{\mathrm{el}}^{2}}{\mathrm{~L}_{\mathrm{m}}^{2}} \mathrm{R}_{1}+\mathrm{R}_{2}^{\prime}\right)\end{array}$ \\
\hline $\begin{array}{l}\text { Equation for finding } \\
\text { extremum }\end{array}$ & $\begin{array}{c}\mathrm{d}\left(\mathrm{I}_{1} / \sqrt{\mathrm{M}}\right) / \mathrm{d} \Delta \omega_{\mathrm{el}}=0 \\
\left(\mathrm{~L}_{\mathrm{m}}+\mathrm{L}_{2 \sigma}^{\prime}\right)^{2}-\mathrm{R}_{2}^{\prime 2} / \Delta \omega_{\mathrm{el}}^{2}=0\end{array}$ & $\begin{array}{c}\mathrm{d} \Delta \mathrm{P} / \mathrm{d} \Delta \omega_{\mathrm{el}}=0 \\
\left\lfloor\left(\mathrm{~L}_{\mathrm{m}}+\mathrm{L}_{2 \sigma}^{\prime}\right)^{2}-\mathrm{R}_{2}^{\prime 2} / \Delta \omega_{\mathrm{el}}^{2}\right\rfloor \cdot \mathrm{R}_{1}+\mathrm{R}_{2}^{\prime} \cdot \mathrm{L}_{\mathrm{m}}^{2}\end{array}$ \\
\hline $\begin{array}{l}\text { Optimal frequency } \\
\text { deviation }\end{array}$ & $\Delta \omega_{\mathrm{el} \mathrm{opt( \textrm {I } )}}=\frac{\mathrm{R}_{2}^{\prime}}{\mathrm{L}_{2}^{\prime}}$ & $\begin{array}{l}\Delta \omega_{\text {el opt }(\Delta \mathrm{P})}=\frac{\mathrm{R}_{2}^{\prime}}{\sqrt{\left(\mathrm{L}_{\mathrm{m}}+\mathrm{L}_{2 \sigma}^{\prime}\right)^{2}+\mathrm{L}_{\mathrm{m}}^{2} \cdot \mathrm{R}_{2}^{\prime} / \mathrm{R}_{1}}} \\
=\frac{\mathrm{R}_{2}^{\prime}}{\mathrm{L}_{2}^{\prime}} \frac{1}{\sqrt{\left(1+\mathrm{L}_{\mathrm{m}}^{2} \cdot \mathrm{R}_{2}^{\prime}\right) / \mathrm{L}_{2}^{2} \cdot \mathrm{R}_{1}}}\end{array}$ \\
\hline $\begin{array}{l}\text { Optimal absolute } \\
\text { slip }\end{array}$ & $\beta_{\mathrm{opt(I)}}=\frac{\mathrm{R}_{2}^{\prime}}{\mathrm{L}_{2}^{\prime} \cdot \omega_{0 \mathrm{el}}}$ & $\beta_{\mathrm{opt}(\Delta \mathrm{P})}=\frac{\mathrm{R}_{2}^{\prime}}{\mathrm{L}_{2}^{\prime} \cdot \omega_{0 \mathrm{el}}} \frac{1}{\sqrt{\left(1+\mathrm{L}_{\mathrm{m}}^{2} \cdot \mathrm{R}_{2}^{\prime}\right) / \mathrm{L}_{2}^{2} \cdot \mathrm{R}_{1}}}$ \\
\hline $\begin{array}{l}\text { Optimal value } \\
\qquad \operatorname{tg} \varphi_{0}^{\prime}\end{array}$ & $\operatorname{tg} \varphi_{0 \text { opt(I) }}^{\prime}=\frac{\mathrm{L}_{2}^{\prime} \Delta \omega_{\mathrm{el} \mathrm{opt(I)}}}{\mathrm{R}_{2}^{\prime}}=1$ & $\begin{array}{c}\operatorname{tg} \varphi_{0 \text { opt }(\Delta \mathrm{P})}^{\prime}=\Delta \omega_{\text {el opt }(\Delta \mathrm{P})} \cdot \frac{\mathrm{L}_{2}^{\prime}}{\mathrm{R}_{2}^{\prime}}= \\
=\frac{1}{\sqrt{\left(1+\mathrm{L}_{\mathrm{m}}^{2} \cdot \mathrm{R}_{2}^{\prime}\right) / \mathrm{L}_{2}^{\prime 2} \cdot \mathrm{R}_{1}}}\end{array}$ \\
\hline $\begin{array}{c}\text { Optimal value } \\
\varphi_{0}^{\prime}\end{array}$ & $\varphi_{0 \mathrm{opt}(\mathrm{I})}^{\prime}=45^{\circ}$ & $\begin{array}{c}\varphi_{0 \text { opt }(\Delta \mathrm{P})}^{\prime}=\operatorname{arctg}\left(\Delta \omega_{\text {el opt }(\Delta \mathrm{P})} \cdot \frac{\mathrm{L}_{2}^{\prime}}{\mathrm{R}_{2}^{\prime}}\right) \\
\varphi_{0 \text { opt }(\Delta \mathrm{P})}^{\prime} \approx 39 \ldots 40^{0}\end{array}$ \\
\hline
\end{tabular}

The functional block diagram of control system used in the experiment is shown in Figure 2. Blocks 1-12 are standard for the frequency control system with the control law $\mathrm{U} / \mathrm{f}=$ const. The block 13 was added to the standard control system in order to introduce an additional set point $\mathrm{f}_{\text {add }}^{*}$ into the frequency setting channel. Output of block 13 goes to the adder that results reference signal to the frequency $\mathrm{f}^{*}$. The correction device in the voltage reference channel is aimed to stabilize the motor shaft rotation speed by changing the voltage amplitude.

The speed reference signal generated in block 16 is subtracted from the actual motor speed. The speed error signal goes to the proportional controller 15 and further to the limiting unit 14 . The resulting correction signal goes to the adder that results the reference amplitude of the supply voltage.

\section{Discussion of the results}

Figure 3 shows the dependences $I_{1}=f(\Delta \omega)$ for different rotation frequencies and load torques of induction motor. Therefore, there is a value $\Delta \omega_{\text {opt }}$ at which the stator current is minimal at the fixed load torque and rotor speed. Figure 4 illustrates the average the optimal values $\Delta \omega_{\text {opt }}$ obtained for different load torques and rotor speeds. The average optimal difference $\Delta \omega_{\mathrm{opt}}$ can be established independent of the rotor speed.

The average optimal differences $\Delta \omega_{\text {opt }}$ between the speed of the stator rotating field and the rotor speed calculated analytically is:

$$
\Delta \omega_{\text {el opt }}=\left(\omega_{e l 1}-\omega \cdot p_{n}\right)_{o p t}=\Delta \omega_{o p t}=\frac{R_{2}^{\prime}}{L_{2}^{\prime}}=\frac{7,73}{0,472}=16,38 \mathrm{rad} / \mathrm{s}
$$




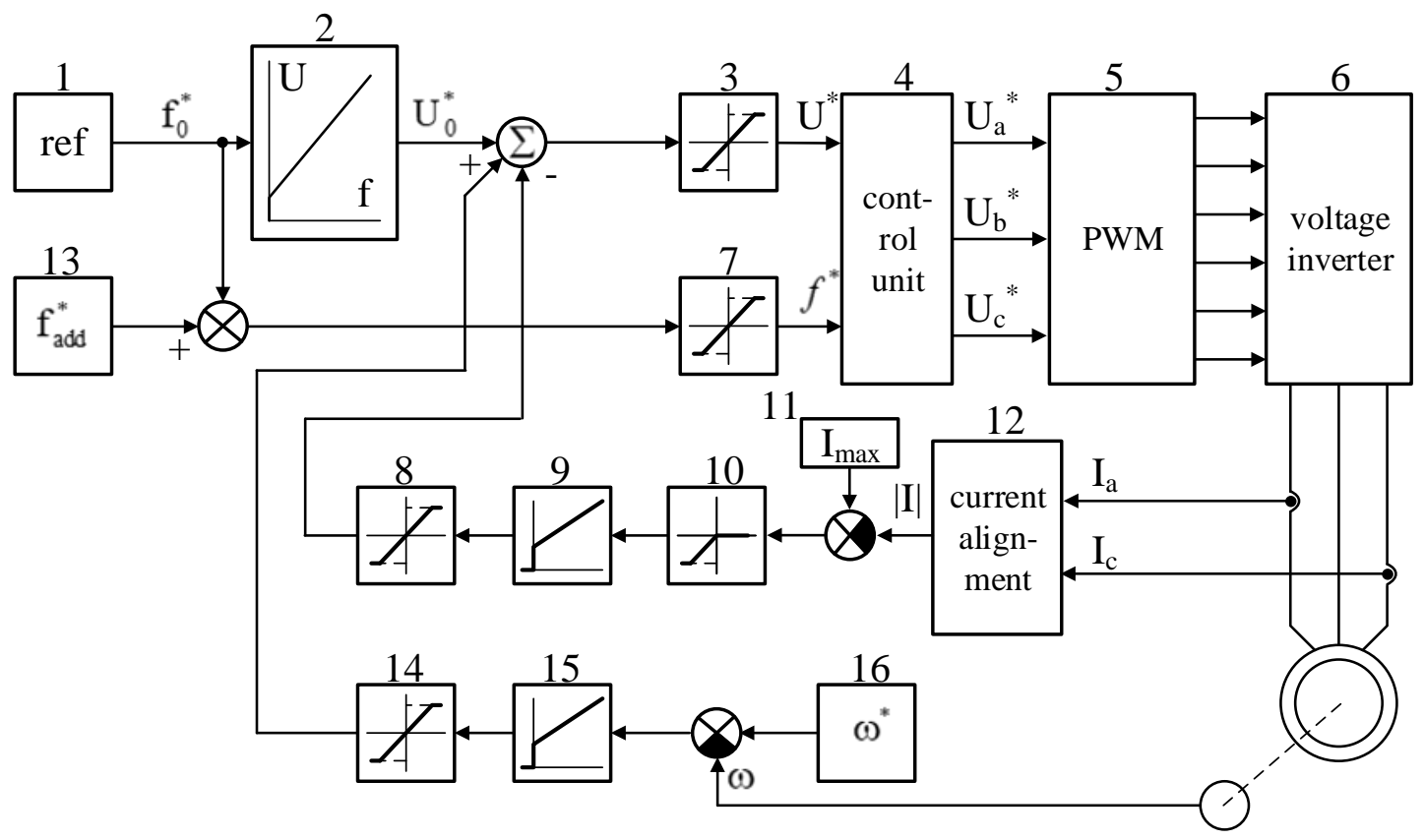

Fig. 2. Functional diagram of the control system of induction motor drive used for the experiment.

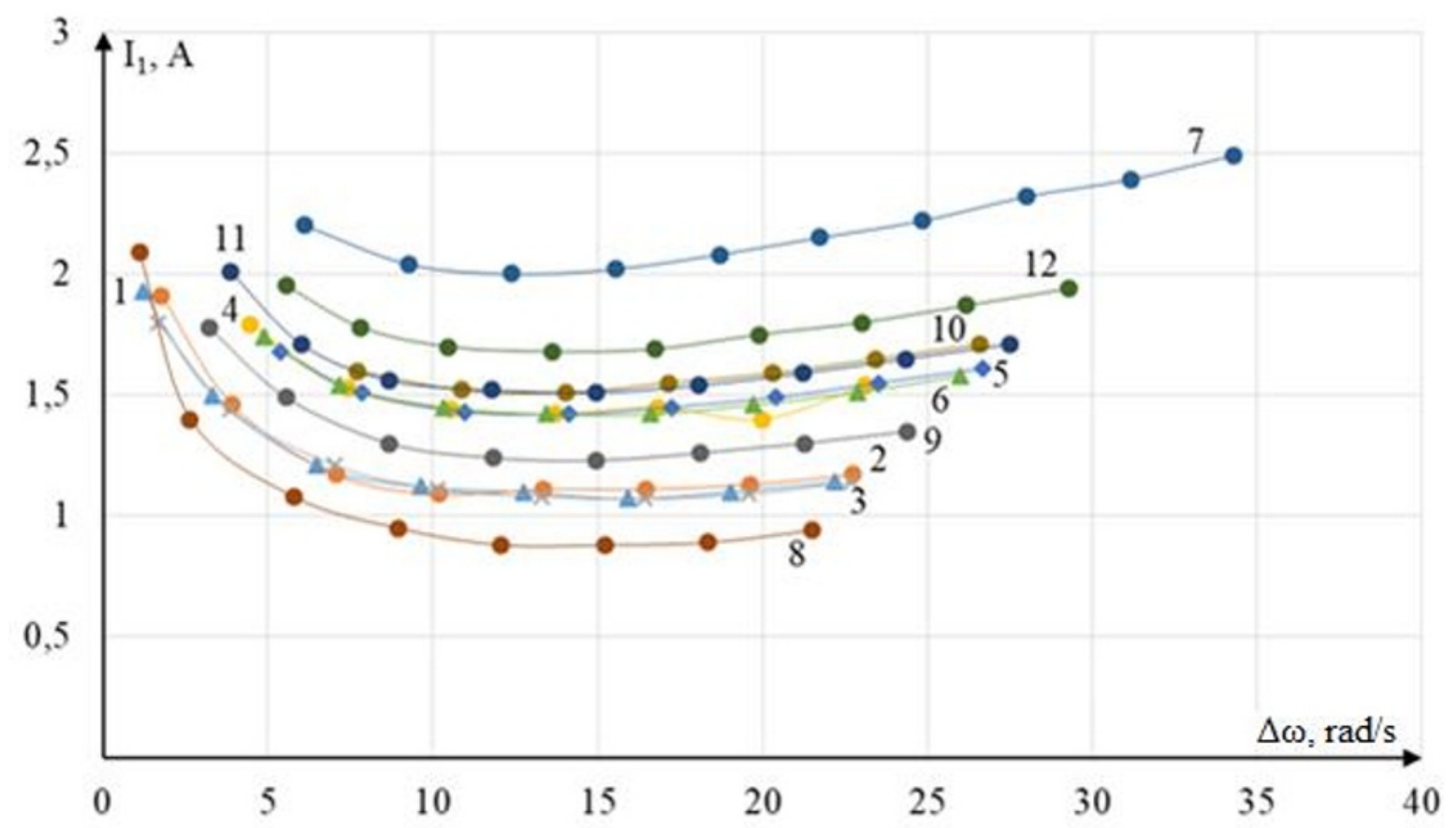

Fig. 3. Stator current $\mathrm{I}_{1}$ dependence on the rotor rotational frequency difference $\Delta \omega$ : 1 - $\omega=0.42$ o.e., $\mathrm{M}=0.28$ o.e.; $2-\omega=0.19$ o.e., $\mathrm{M}=0.28$ o.e.; 3 - $\omega=0.86$ o.e., $\mathrm{M}=0.28$ o.e.;

4- $\omega=0.17$ o.e., $\mathrm{M}=0.5$ o.e.; 5 - $\omega=0.39$ o.e., $\mathrm{M}=0.5$ o.e.; $6-\omega=0.84$ o.e., $\mathrm{M}=0.5$ o.e.;

7- $\omega=0.29$ o.e., $\mathrm{M}=1$ o.e.; $8-\omega=0.65$ o.e., $\mathrm{M}=0.19$ o.e.; 9 - $\omega=0.63$ o.e., $\mathrm{M}=0.38$ o.e.; $10-\omega=0.26$ o.e., $\mathrm{M}=0.57$ o.e.; $11-\omega=0.72$ o.e., $\mathrm{M}=0.57$ o.e.; $12-\omega=0.81$ o.e., $\mathrm{M}=0.7$ o.e.

Further, we implemented experiment on squirrel cage induction motor and obtained optimal values $\Delta \omega_{\mathrm{opt}}$. Comparison of the analytical and experimental results performed good convergence. The average relative difference between the values obtained does not exceed $8 \%$.

\section{Conclusions}

1. Experimentally proven the possibility of obtaining near-optimal modes of frequency regulated induction electric drive. The minimal ratio "stator current/motor 


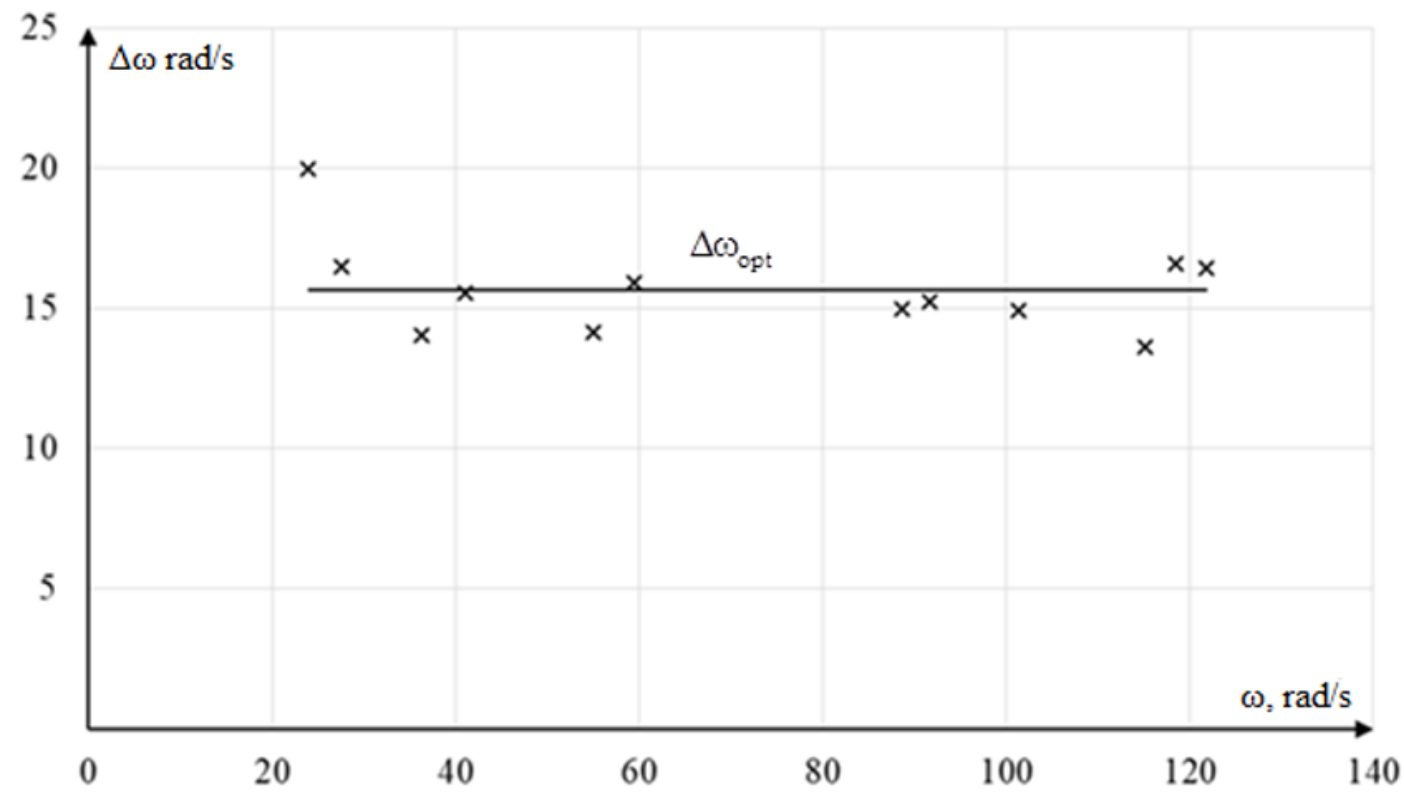

Fig. 4. Dependence of the optimal rotor speed difference $\Delta \omega$ on the rotor speed $\omega$.

torque" is achieved when the absolute slip has the optimal value $\beta_{\mathrm{opt}(\mathrm{I})}=\frac{\mathrm{R}_{2}^{\prime}}{\mathrm{L}_{2}^{\prime} \cdot \omega_{0 \mathrm{el}}}$ and $\operatorname{tg} \varphi_{0}^{\prime}=1$.

2. To implement the optimal mode with a minimum of the "stator current / motor torque" ratio, it is necessary to adjust the voltage applied to the stator winding with respect to the linear frequency regulation law $\mathrm{U} / \mathrm{f}=$ const.

This research was supported by grant RFBR 19-48-480001 "Development, investigation and optimization of energy-saving electrical and electrically driven automated systems for plasma, electrometal slag and induction technologies and units".

\section{References}

[1] V.Ya. Ushakov, Isolyatsiya ustanovok Blaschke F.A., 1971 New Method for Structural Decoupling of A.C. Induction Machines. Proceedings of the Conference Rec. IFAC (Duesseldorf, Germany) 1-15 (1994)

[2] I. Boldea, A. Moldovan, L. Tutelea, Scalar V/f and I-f control of AC motor drives: An overview. 2015 Intl Aegean Conference on Electrical Machines \& Power Electronics (ACEMP), 2015 Intl Conference on Optimization of Electrical \& Electronic Equipment (OPTIM) \& 2015 Intl Symposium on Advanced Electromechanical Motion Systems (ELECTROMOTION) (Side) 8-17 (2015)

[3] J.M. Peña, E.V. Díaz, Implementation of $V / f$ scalar control for speed regulation of a three-phase induction motor. ANDESCON. Arequipa. 1-4 (2016)

[4] I. Takahashi, T. Noguchi, A New Quick Response and High Efficiency Control Strategy for an Induction Motor. IEEE Trans. Ind. Appl. IA-22, 820827 (1985)
[5] J. Rodriguez, R.M. Kennel, J.R. Espinoza, M. Trincado, C.A. Silva, C.A. Rojas, High performance control strategies for electrical drives: an experimental assessment. IEEE Trans. Ind. Electron. 59, 812-820 (2012)

[6] H. Rehman, Detuning minimization for alternative energy vehicular drive system. IEEE Vehicle Power and Propulsion Conference, Seoul. 42-47 (2012)

[7] R. Issa, Three-Phase Induction Motor Stator Current Optimization. IJCA Special Issue on Evolutionary Computation 2, 41-50 (2010)

[8] A. Boukhelifa, M. Kherbouch, A. Cheriti, R. Ibtiouen, O. Touhami, R. Tahmi, Stator current minimization by field optimization in induction machine. International Conference on Electrical, Electronic and Computer Engineering, ICEEC'04 10.1109/ICEEC.2004.1374611 (2004)

[9] S. Lim, K. Nam, Loss-Minimizing Control Scheme for Induction Motors. IEEE Proc. - Electr. Power Appl. 151(4), (2004)

[10] T. Chelliah, S. Srivastava, P. Agarwal, Energy Efficient Control of Three-Phase Induction Motor - A Review. International Journal of Computer and Electrical Engineering. 1(1), 61-70 (2009)

[11] R. Issa, H. Sarhan, Improving Mechanical Characteristics of Inverter- Induction Motor Drive System. American Journal of Applied Sciences. 3(8), (2006)

[12] B.K. Bose, Modern Power Electronics and AC Drives, Prentice Hall (2007)

[13] B. Singh, B.N. Singh, Experience in the design optimization of a voltage source inverter fed squirrel cage induction motor. Electric Power Systems Research. 26, 155-161 (1993)

[14] R. Issa, The Effect of Non- Nominal Voltage on Indices of AC Drive Systems. Journal of Engineering Studies \& Research, Baghdad, 2(1), (1997) 
[15] B.B. Palit, Energy saving operation at induction motors by voltage reduction at no-and low partial load. Proc. IEEE Ind. Appl. Annual Meeting pp 147-151 (1989)

[16] S.A. Kovchin, Theory of electric drive [Text] Saint-Petersburg: Energoatomizdat 496 (2000)

[17] V.I. Klyuchev, Theory of electric drive: the Textbook for high schools. - 2 nd ed. revised. and add. [Text]. Moscow: Energoatomizdat 704 (2001)

[18] G.G. Sokolovsky, 2006 AC electric drives with frequency control [Text] Moscow: «Akademia» 272

[19] V.N. Meshcheryakov, V.S. Cherkasova, and Meshcheryakova O.V., Correction of system of vector control of the asynchronous electric drive [Text] Control system and information technologies. 3(61), 36-38 (2015)

[20] V.N. Meshcheryakov, P.N. Levin, Optimization of mutual position of stator current vectors and magnetic flux of induction motor under vector control [Text] Proceedings of Universities. Electromechanics 1, 25-27 (2006)

[21] R.T. Schreiner, Y. Dmytrenko, Optimal frequency control of asynchronous electric drive [Text] Kishinev: Shtiintsa. 223 (1982)

[22] V.N. Meshcheryakov, V.G. Karantayev, Application of the search-free adaptive system for control of the electric drive with the valve motor [Text] Electrotechnical complexes and systems 2, 38-40 (2006) 